\title{
Simulation of Switched Reluctance Generator in Low and Medium Speed Operations for Wind Energy Application
}

\author{
A. Arifin, I. H. Al-Bahadly, and S. C. Mukhopadhyay \\ School of Engineering and Advanced Technology, Massey University, Tennent Drive, Palmerston North 4474, New Zealand \\ Correspondence should be addressed to A. Arifin, a.arifin@massey.ac.nz
}

Received 5 April 2012; Accepted 10 July 2012

Academic Editors: H. K. Ozturk and M. Souliotis

Copyright ( 2012 A. Arifin et al. This is an open access article distributed under the Creative Commons Attribution License, which permits unrestricted use, distribution, and reproduction in any medium, provided the original work is properly cited.

This paper provides a new approach to maximize the amount of power generated by the switched reluctance generator (SRG) in the low and medium speed operations. There are many control variables which affect the power generated such as: firing angles, reference current, speed and voltage. It will incur high costs and time consuming to modify the variables using experimental set up. Hence, to minimize time, cost and aid in the manufacturing industry, a simulation model of the overall SRG drive is developed. The objective of the work is to identify the optimal parameters and characterize them under closed loop control. The study indicates that there is an optimal voltage, firing angles and reference current at each speed range. Also, the percentage of the power generated can be categorized as a function of dwell angle and speed at optimal voltage level. The optimal dwell angle is determined using the least square method. Within the closed loop system, the high percentage of power generated can be maintained by adjusting the voltage level. It allows operation in single pulse mode as opposed to the conventional current chopping during the low and medium speed.

\section{Introduction}

Development of switched reluctance machine (SRM) as a motor has been rapid especially in the areas of hybrid electrical vehicles [1-4], aerospace integral starter/generator [5-8], system and also in domestic appliances such as washing machine and vacuum cleaner. It has attracted many researches due to its robust and simple design as well as the ability to operate over a wide speed range. Little however has been done on the study of the machine in generating mode.

This paper is focused on the development of the SRG for wind energy application which is categorized under the low and medium-speed range.

Some studies relative to this issue have been reported. Several publications offered their contribution to the development and study of the SRG in wind energy applications [9-12]. The research, however, is limited to exploring the different types of control for operation of SRG in variable speed applications.

There are also studies in the area of optimal control, machine structure and converter requirement [13]. In [1418 ], investigations on the number of stator and rotor poles on machine performance have been made. They have come to an agreement that low number of poles are for high-speed application whereas a high number of poles relate to lowspeed application. However, at this stage of research there is no right combination which gives optimum performance.

A number of literatures regarding control optimization have also been reported. An algorithm to determine optimal angles based on correct balance between efficiency and low torque ripple has been proposed [19]. The method relies heavily on shape/adjacent phase current and requires certain parameters to be determined experimentally. Furthermore the output power generated catered for certain load requirement. Curve fitting has been used to characterize the optimal angles as a function of power and speed level [20]. However the study is focused on high-speed automotive application. Iterative method to identify and classify design parameters based on its application in highspeed range has also been studied [21]. But this did not include any development of function or procedure relating the optimized parameters with machine performance. For those reported methods, the research is limited to highspeed operation. Only [22] has reported on optimization 
during current controlled operation. Although different control strategies have been proposed, the common features amongst these studies in the literature are focused on optimization of firing angles in terms of minimizing losses.

The conventional excitation circuit used for SRG is the asymmetric half bridge converter (AHBC). However, studies have been undertaken to minimize cost by reducing number of components in the converter circuit $[23,24]$. The best option of converter to be used has yet to be defined.

While a number of papers on SRG in wind energy applications have been published, a comprehensive study discussing the effect of different variables and how to maximize the generated power are not available. Different from the previously reported objectives, this study determines the optimal variables by investigating the impact of the controlled variables/parameters in terms of the power generated by the machine. A dynamic control and performance are presented. By adjusting the voltage level, generated power is maximized using single pulse mode operation during the low- and medium-speed range as opposed to the conventional current chopping mode.

In this work, a simulation model of a three-phase 12/8 machine is developed to analyze the different types of variables associated with the generated power. It integrates the overall SRG drive and provides a platform to modify control variables in order to minimize cost and manufacturing time. An optimization function based on the optimal variables is proposed. The simulation work demonstrates that the model and the proposed method can be used to aid in selecting the best/optimal operation of SRG for wind energy application.

\section{Characteristics of Generating Operation}

2.1. Magnetic Characteristics of SRG. In order to model/ analyze the machine, the SRG can be represented by the voltage equation across one phase winding. Since the mutual coupling between phases for double salient pole machine is small, it can be neglected [25] and the voltage can be represented as

$$
V=R i+\frac{d \psi(i, \theta)}{d t} .
$$

The flux linkage, $\psi$, is a function of phase current, $i$, and rotor position, $\theta$. The phase winding resistance, $R$, cannot be ignored during low-speed operation. The phase current may be low during initial excitation, but it increases as inductance profile decreases. However, at high speed current is low hence voltage drop across the phase winding may be ignored. Furthermore, the effect of change in resistance with temperature as a result of increase in the current is also small for the SRM. Hence (1) is commonly used to represent the voltage across phase winding $[26,27]$.

The instantaneous electromagnetic torque produced by each phase is derived from the partial derivative of coenergy, $W$, with respect to the rotor position,

$$
T(i, \theta)=\frac{d W(i, \theta)}{d \theta},
$$

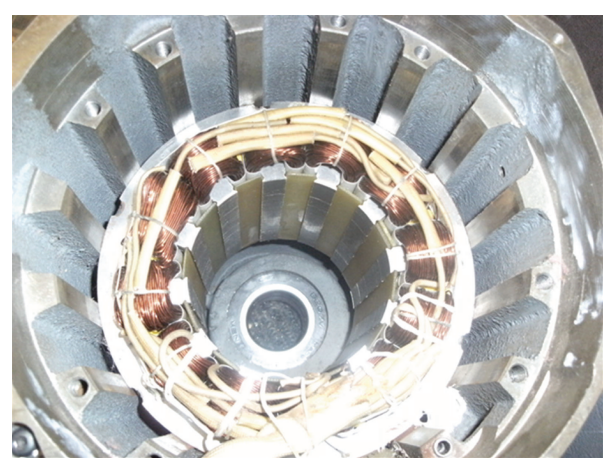

(a)

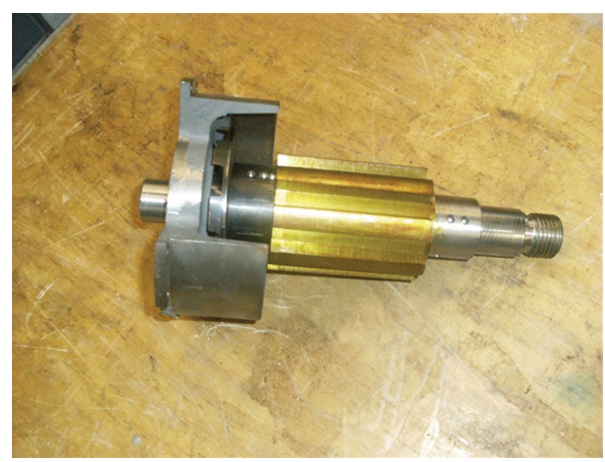

(b)

Figure 1: Configuration of a 3-phase 12/8 machine under study (a) stator $(\mathrm{b})$ rotor.

where,

$$
\left.W\right|_{\theta=\mathrm{const}}=\int_{0}^{i} \psi d i
$$

The model of the machine which takes into account the magnetic nonlinearities is modeled by the nonlinear flux-current-angle $(\varphi-i-\theta)$ characteristics and developed according to (1). The flux linkage characteristic can be obtained via static measurement of the voltage and current at various rotor positions or by using the Finite Element Method (FEM) [28-30]. In the field of electrical machines, FEM analysis is well known to determine the machine characteristics [28]. However, the experimental test is used to validate the data and the FEM analysis itself.

\subsection{Experimental Verification of Magnetic Characteristics.}

The accuracy of flux linkage estimation obtained by the FEM is validated by measurements on the prototype three-phase, 12/8 SRG depicted in Figure 1 whose parameters are listed in Table 1.

The flux linkage curves in Figure 2 were plotted at three different rotor positions, aligned, midway, and unaligned for various phase currents. The test method injects a voltage pulse to turn on the switch whilst waveforms of current and voltage across the phase winding is recorded $[8,28]$. The flux 


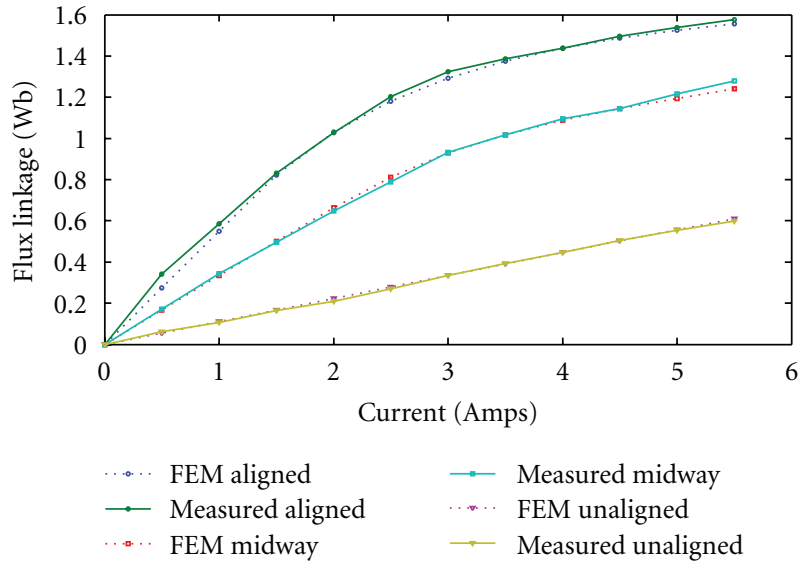

FIgURE 2: Comparison of flux linkage characteristic between experimental and FEM for a 12/8 SRG.

TABLE 1: SRG parameters.

\begin{tabular}{lc}
\hline Rotor pole pitch & $45^{\circ}$ \\
Phase winding resistance, $R_{\mathrm{ph}}$ & $9.85 \Omega$ \\
Number of rotor pole, $N_{r}$ & 8 \\
Number of stator pole, $N_{s}$ & 12 \\
Number of phases, $m$ & 3 \\
Aligned position & $22.5^{\circ}$ \\
Unaligned position & $0^{\circ}$ \\
\hline
\end{tabular}

linkage for one fixed position is obtained by rearranging (1) such that

$$
\psi=\int(V-R i) d t
$$

In Figure 2 a good agreement is observed between the FEM obtained results and the measured ones; thus the validity of the magnetic field analysis using FEM was proven. The machine model consists of two look up tables: inverse of flux linkage $i(\varphi, \theta)$ and the static torque $T(i, \theta)$.

2.3. Criteria for Generating Operation. The best generating operation for SRG in wind energy application is to maximize the power generated at various wind velocity. Therefore, one criterion has been identified based on the operation of the generator to maximize power generation.

The maximum percentage of power generated is evaluated through

$$
\text { \%gen_power }=\frac{v_{\text {gen }} \cdot i_{\text {gen }}}{v_{\text {gen }} \cdot i_{\text {gen }}+v_{\text {exc }} \cdot i_{\text {exc }}},
$$

where $v_{\mathrm{gen}}, v_{\mathrm{exc}}$ are the average generated and excitation voltage $i_{\text {gen }}, i_{\text {exc }}$ are the average generated and excitation current.

Total losses in the machine including copper and iron loss should be considered for the optimization. In this study the optimization is carried out during each value of reference current, voltage, and speed. Hence iron loss which depends on flux density and frequency is assumed constant. Furthermore the speed range in this study is limited to below $55 \mathrm{rad} / \mathrm{s}$. Iron loss becomes the dominant component of losses at higher speed [31]. Since wind energy is categorized under the low- and medium-speed range therefore only copper losses are included in the calculation since they vary with the phase current. The average power for three-phase machine computed using instantaneous voltage and current is:

$$
P_{\text {total }}=\left(\frac{1}{T} \int_{0}^{T}\left(v i-i^{2} R\right) d t\right) .
$$

Having a high percentage of power generated implies that the losses are minimized. The effect of variable parameters on the previous criteria aids in developing a control method to optimize the generating operation of the machine.

\section{Modeling of Switched Reluctance Generator}

The switched reluctance generator can be represented as a mathematical model comprising electrical and mechanical sections. The electrical section is built based on the phase voltage equation (1) whereas the mechanical section is based on the movement equation. An asymmetric half bridge converter (AHBC) circuit and hysteresis current controller are employed for this study. The complete SRG drive can be integrated as in Figure 3.

The SRG drive systems were integrated using MATLABSimulink software. A good simulation model aids to reduce cost and time from having to set and reset the experimental design [8]. From Figure 3 the parameters which affect the generated power are turn on and turn off angle, terminal voltage, and reference current.

3.1. Effects of Reference Current. Reference current was chosen as an appropriate control variable when operating in the low-speed range. It is obtained through voltage, speed or power regulation. To analyze its effect on generated power, it is made constant.

Figure 4 illustrates the effect of reference current between $1 \mathrm{~A}$ to $9 \mathrm{~A}$, and the results in Figure 4(a) show the difference of percentage power generated for various turn on angles selected before and after alignment position. The turn off angle is kept constant at $38^{\circ}$. The higher the reference current is, the more the energy required for excitation hence reducing the power generated.

For turn on angle of $18^{\circ}$, the turn off angle is varied between $30^{\circ}, 35^{\circ}$, and $40^{\circ}$ in Figure $4(\mathrm{~b})$. Higher percentages of power generated are achieved at higher turn off angle.

Voltage level between $50 \mathrm{~V}$ and $150 \mathrm{~V}$ gives higher percentage of power generated as shown in Figure 4(c).

At various speed, Figure 4(d) shows that percentage of power increases as speed increases. It can be observed that at, reference current of $5 \mathrm{~A}$, high percentage of power generated is obtained as firing angles, voltage, and speed are varied. For this reason we chose 5(a) as our reference current. 


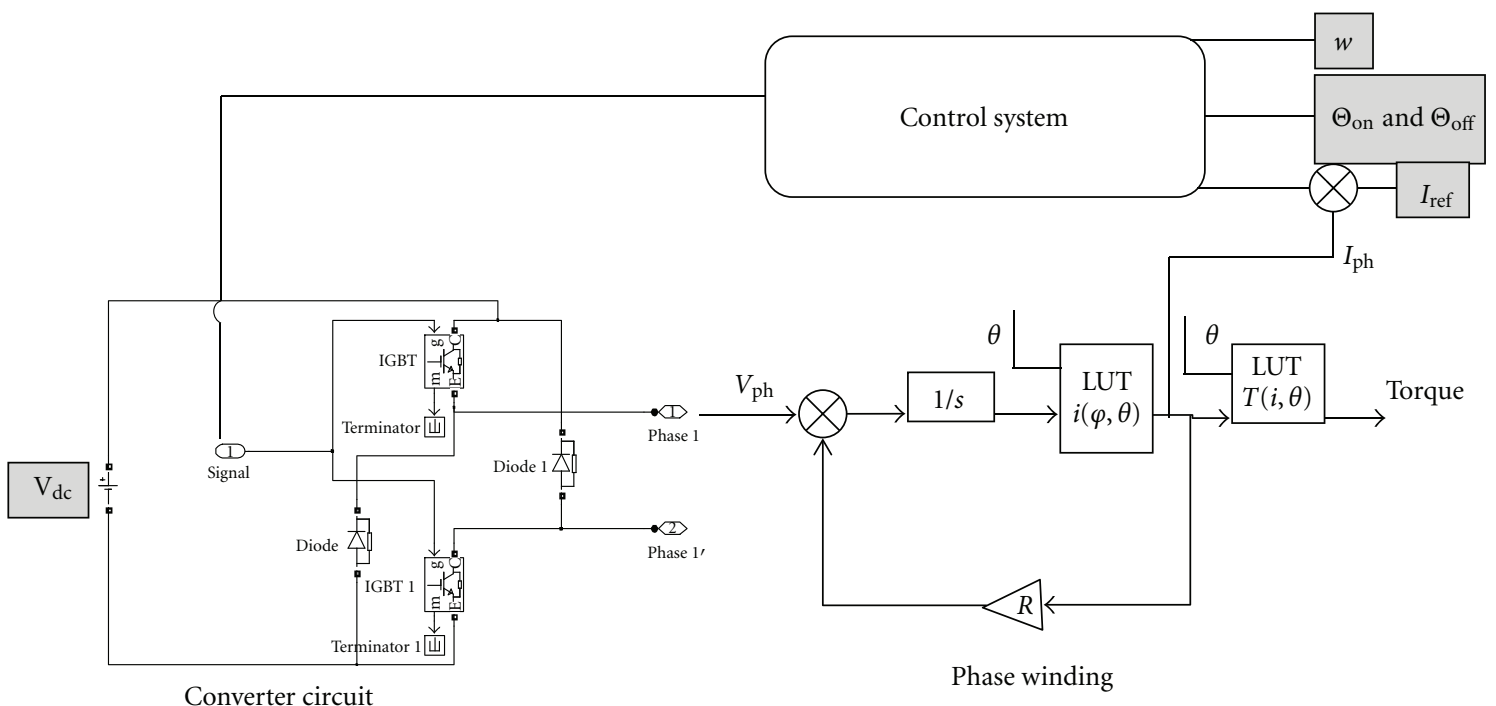

FIGURE 3: Complete model of SRG drive including machine, converter, and control system using MATLAB/Simulink.

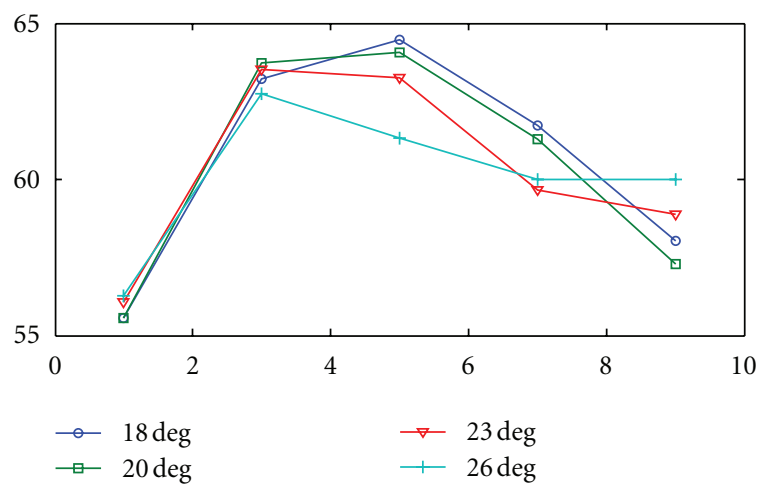

(a)

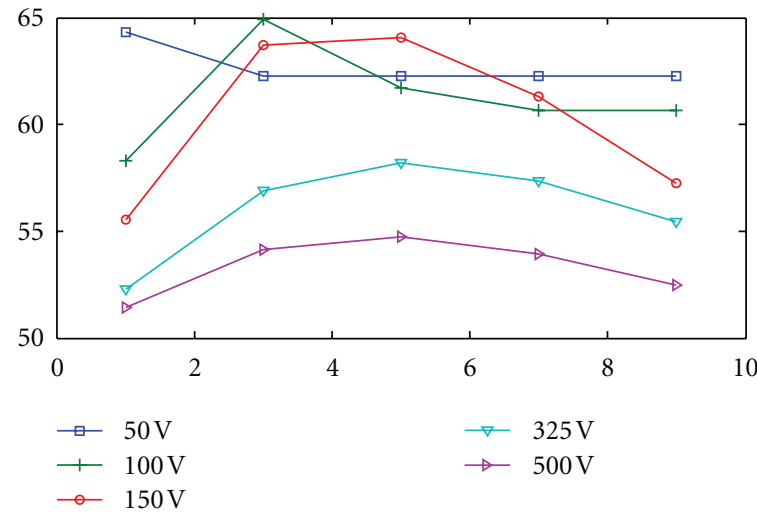

(c)

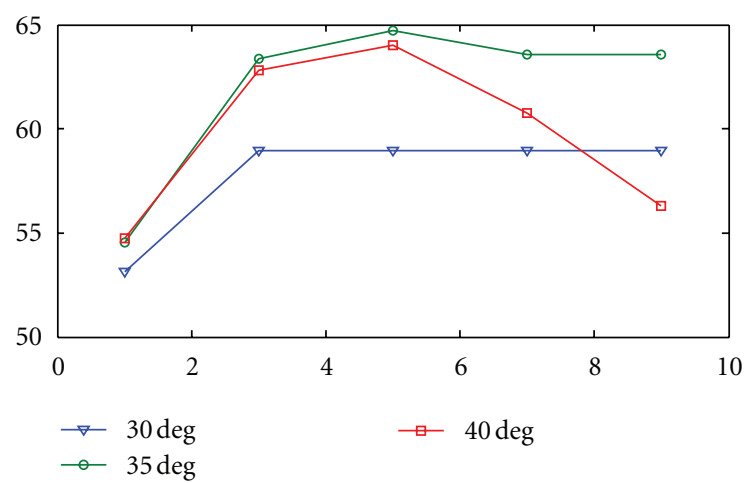

(b)

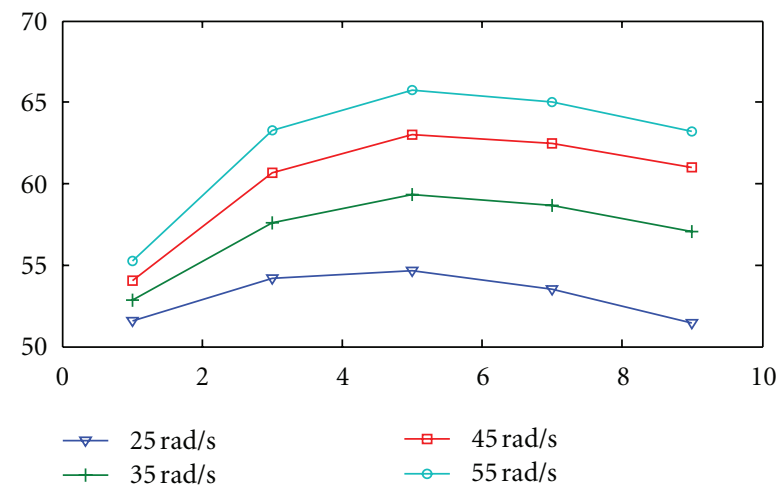

(d)

FIGURE 4: Graph of \% power generated against reference current. Effect of reference current with (a) turn on angle, (b) turn off angle, (c) terminal voltage, and (d) speed.

3.2. Effects of Terminal Voltage. Increasing the terminal voltage reduces the time to reach the reference current. Higher voltage results in faster decrease in current after turn off angle due to the more/higher negative voltage, thus reducing the generated power.
Figure 5 shows variation of terminal voltage with different control variables. Increasing the terminal voltage results in lower percentage of generated power for turn on angle made before and after alignment position as in Figure 5(a). Excitation of machine prior to alignment position gives 


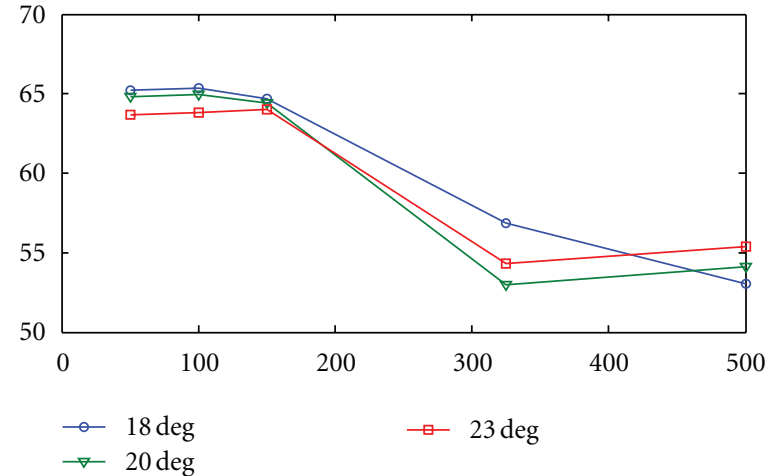

(a)

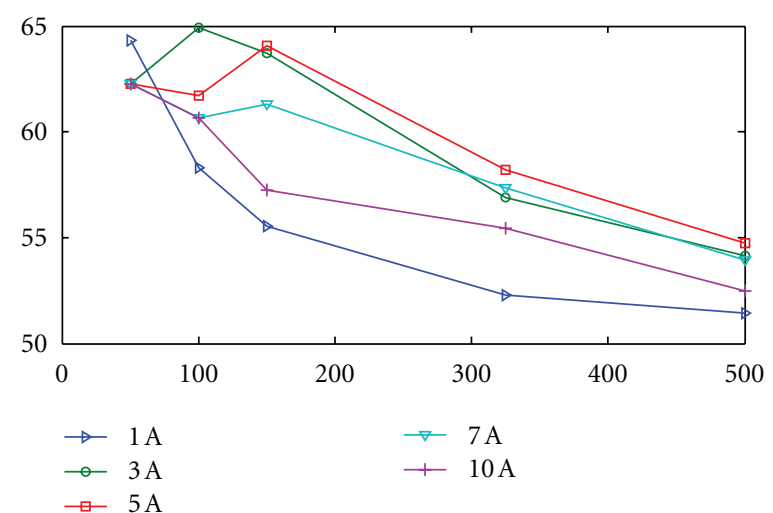

(c)

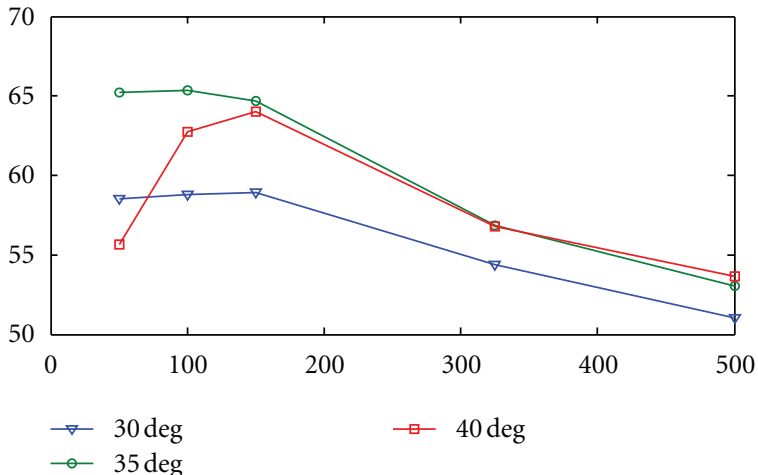

(b)

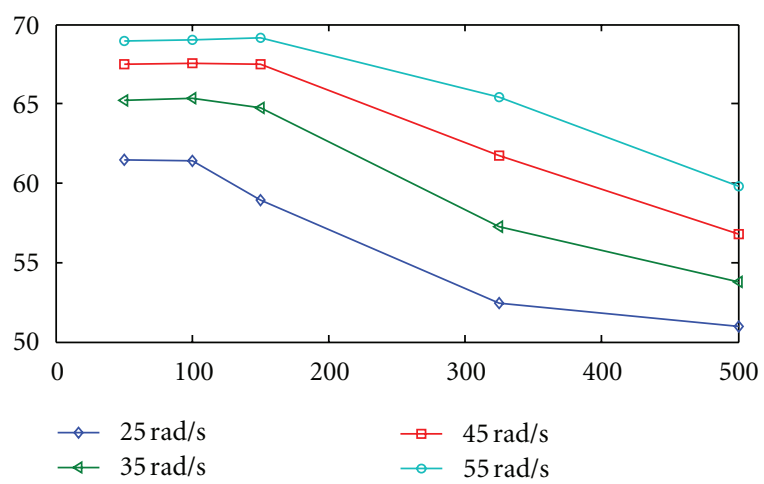

(d)

FIGURE 5: Graph of \% power generated against terminal voltage. Effect of terminal voltage with (a) turn on angle, (b) turn off angle, (c) reference current, and (d) speed.

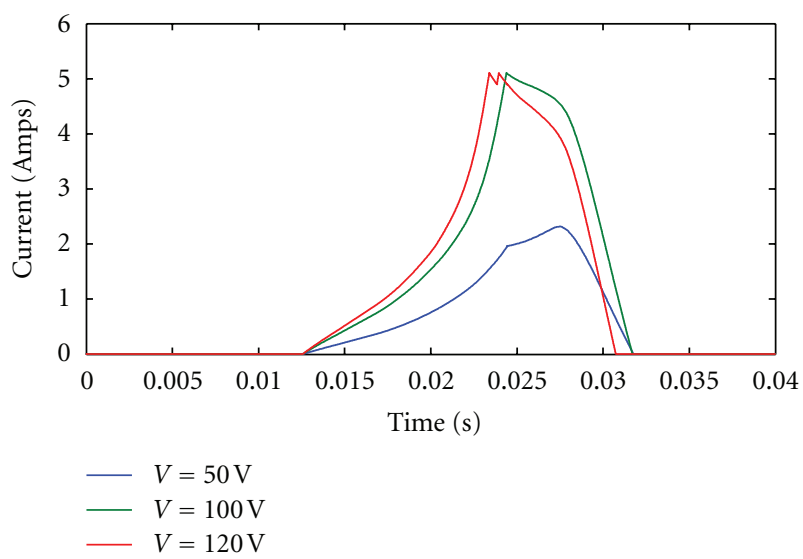

Figure 6: Effect of terminal voltage on shape of phase current at turn on angle $18 \mathrm{deg}$ and turn off angle $35 \mathrm{deg}$ at speed of $25 \mathrm{rad} / \mathrm{s}$.

better percentage of generated power because the generated phase current will keep rising as a result of falling inductance for the excited phase. Larger turn off angle gives better percentage of power generated at turn on angle of $18^{\circ}$ as in Figure 5(b).

In Figure 5(c) the 5 $\mathrm{A}$ reference current has highest percentage of power generated at voltage level of $150 \mathrm{~V}$ and above whereas for voltage below $150 \mathrm{~V}$, reference current of $3 \mathrm{~A}$ gives the highest percentage of power generated. Increasing the reference current whilst keeping the firing angles constant would result in current not being able to reach its reference limit thus resulting in single pulse mode operation.

The percentage of power generated reduces as voltage level is increased for various speeds as in Figure 5(d). Increasing the terminal voltage provides more excitation energy for the current to reach its reference value to operate in current chopping mode. The effect of increasing voltage on the shape of phase current for a certain value of firing angle is shown in Figure 6. The amount of power generated reduces as chopping action is approached.

It can be concluded that the selection of voltage level for excitation will determine the shape of the current either in single pulse mode or current chopping. The range of optimal voltage is between $50 \mathrm{~V}$ and $150 \mathrm{~V}$ for speed between $25 \mathrm{rad} / \mathrm{s}$ to $55 \mathrm{rad} / \mathrm{s}$. 


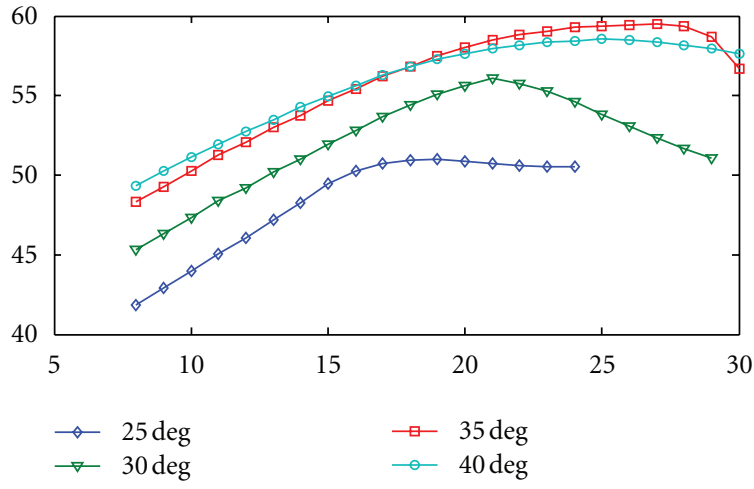

(a)

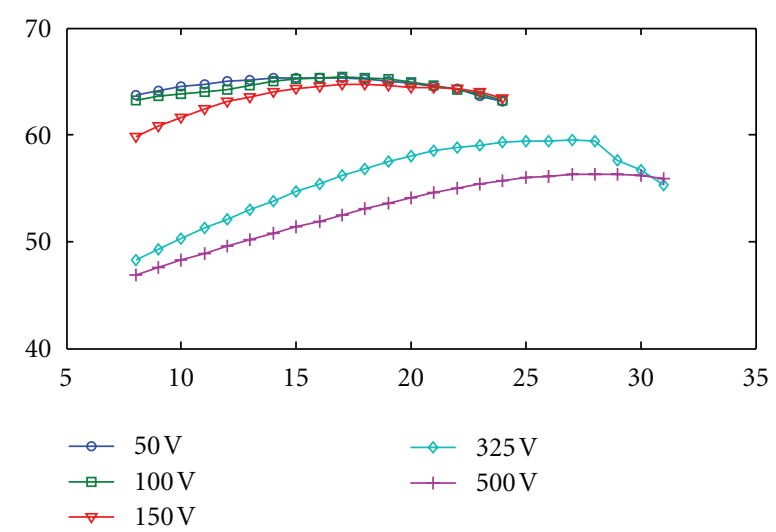

(c)

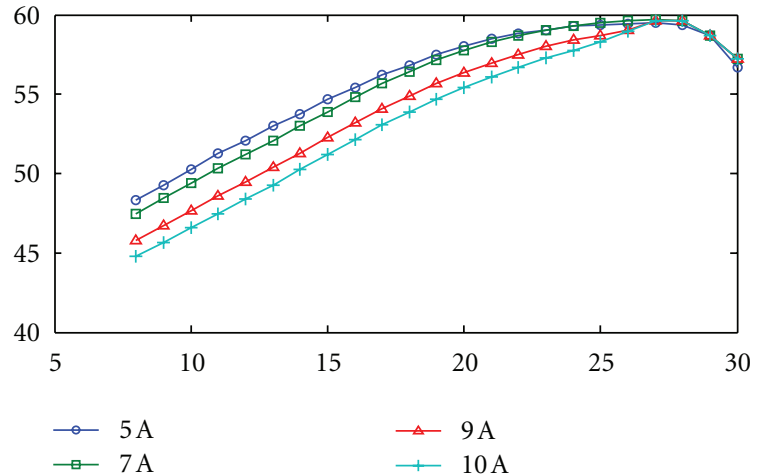

(b)

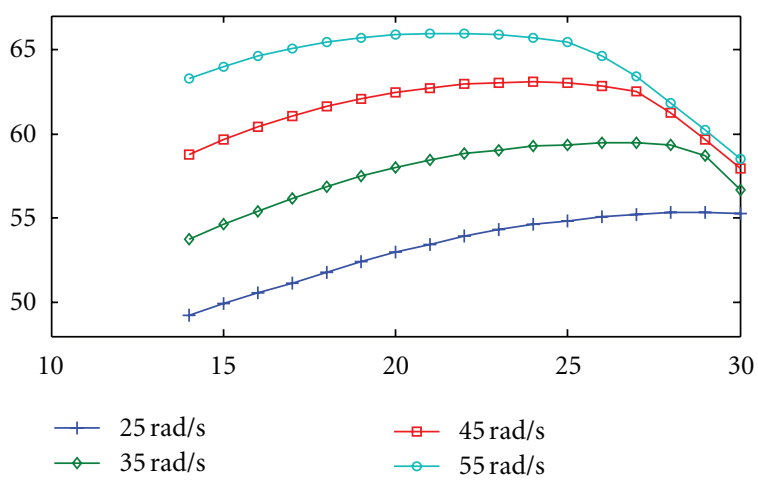

(d)

FIGURE 7: Graph of \% power generated against turn on angle. Effect of turn on angle with (a) turn off angle, (b) reference current, (c) terminal voltage, and (d) speed.

At each voltage level there is a maximum percentage of power generated. Although the generated power produced at high voltage is higher in amount as compared to the low voltage, its excitation and losses are also higher. It can be concluded that voltage level plays a role to maximize the percentage power generated by the SRG.

3.3. Effects of Firing Angles. It has been shown in several literatures that the firing angles impact the power generated [32]. At low speed it is important to shorten the time for current to reach its reference limit. One of the ways to aid in fast increase of phase current is to advance the turn on angle into the decreasing inductance profile. However advancing the turn on angle further into the decreasing inductance profile shortens the dwell angle. Also the further turn on angle is placed along the decreasing inductance profile; the turn off angle is pushed into the minimum inductance region, thus reducing the generated power. The only energy being returned is the stored energy. During this time, energy will not be extracted from prime mover due to zero torque. Figures 7 and 8 illustrate the effects of the turn on and turn off angles with other control variables.
Turn On Angle. The following can be observed for variation of the turn on angle with turn off angle in Figure 7(a) when the SRG is subjected to voltage level of $325 \mathrm{~V}$ and speed of $35 \mathrm{rad} / \mathrm{s}$ : (1) larger turn off angle gives high percentage of power generated; (2) at each turn off angle there exists an optimal value of turn on angle.

Figure 7 (b) shows the variation of turn on angle with various reference current. It can be seen that the highest percentage of power generated occurs when turn on angle is prior to and along the decreasing inductance profile.

Observation in Figure 7(c): (1) for voltage level between $50 \mathrm{~V}$ to $150 \mathrm{~V}$, turn on angle is made prior to alignment position to achieve high percentage of power generated. (2) at higher voltage level, turn on angle is made after alignment position to achieve the highest percentage of power generated.

Variation of turn on angle with speed is given in Figure $7(\mathrm{~d})$. It shows that there exists an optimal value of turn on angle for each speed. The graph tends to converge to one value due to the constant turn off angle used. As turn on angle moves along the decreasing inductance profile, dwell angle reduces and therefore percentage of power generated decreases. 


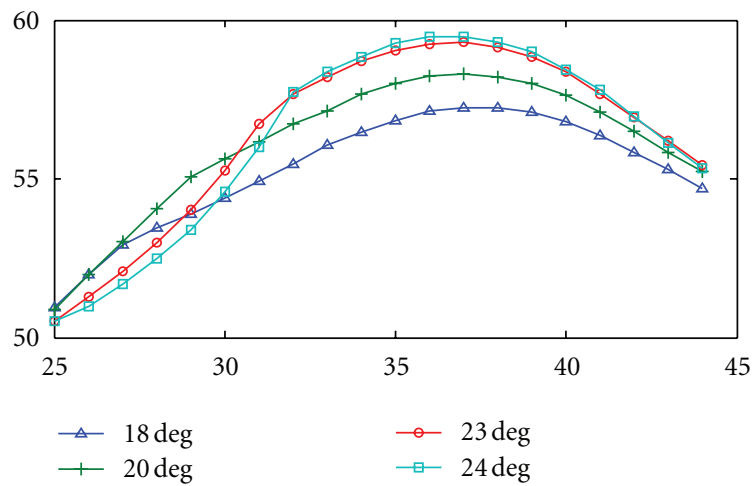

(a)

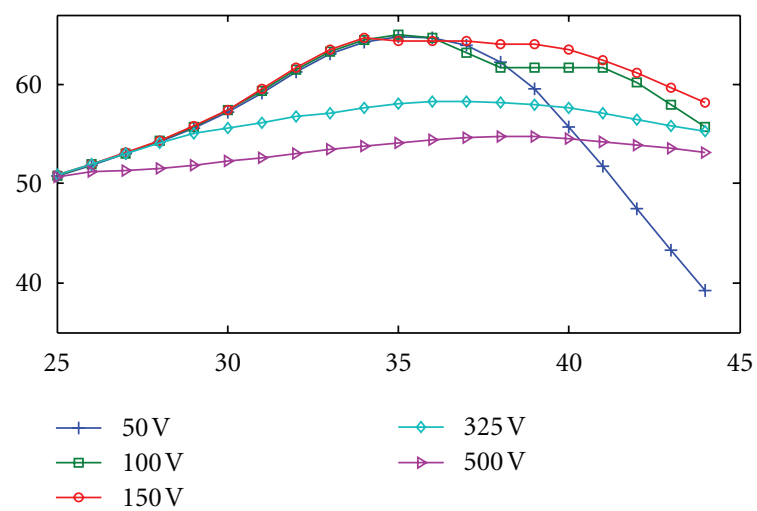

(c)

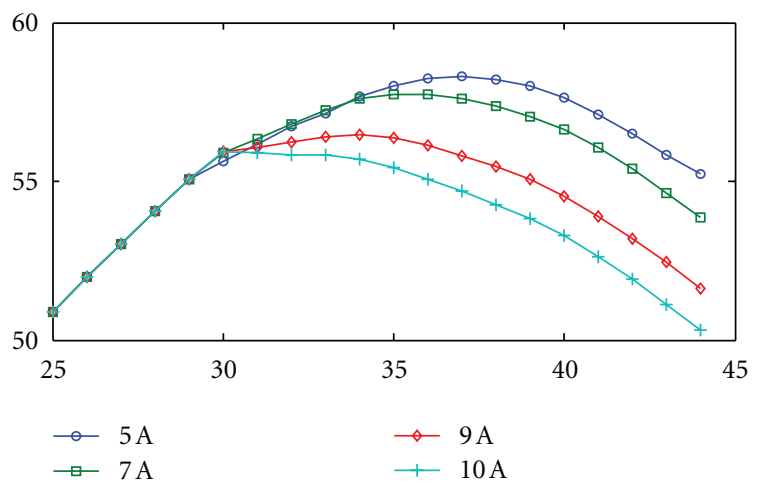

(b)

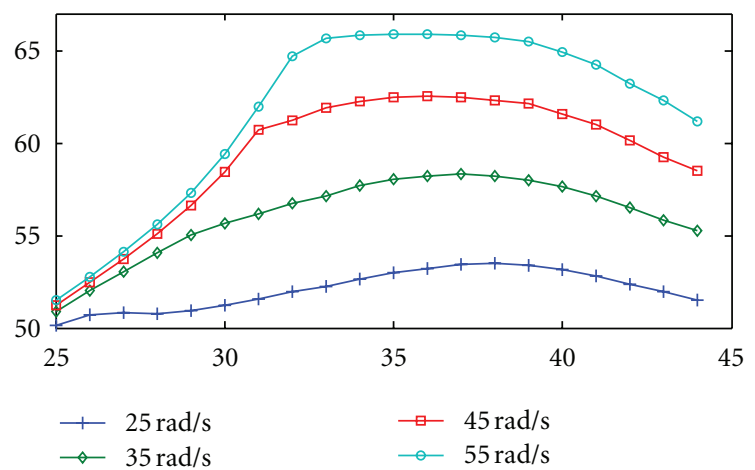

(d)

Figure 8: Graph of \% power generated against turn off angle. Effect of turn off angle with (a) turn on angle, (b) reference current, (c) terminal voltage, and (d) speed.

Turn Off Angle. Figure 8 illustrates the effect of turn off angle with variable control parameters. In Figure $8(\mathrm{a})$, its effect with turn on angle at speed of $35 \mathrm{rad} / \mathrm{s}$ and voltage level of $325 \mathrm{~V}$ is observed. It shows that there is an optimal turn off angle for each turn on angle.

At various turn off angles, the effect of reference current is shown in Figure 8(b) when the SRG operates at voltage level of $325 \mathrm{~V}$ and turn on angle of $18^{\circ}$. The optimal value of turn off angle differs for each reference current level. The highest power generated occurs at reference current of 5A.

The effect of turn off angle at various voltage levels is depicted in Figure 8(c). The optimal working voltage level is within $50 \mathrm{~V}$ to $150 \mathrm{~V}$. Larger turn off angle results in decrease of power generated. Also at large turn off angle there is a possibility of phase current returning to zero/tailing off into the motoring region.

Figure 8 (d) illustrates the effect of turn off angle with speed ranging from $25 \mathrm{rad} / \mathrm{s}$ to $55 \mathrm{rad} / \mathrm{s}$. The range of optimal turn off angle is almost constant for various turn on angle, reference current, voltage level, and speed. It can be said that turn off angle has considerable effects on maximizing the generated power under generating operation.

\section{Optimization of Control Parameters}

The discussion in Section 3 shows that the percentage of power generated is affected by the control parameters such as reference current, terminal voltage, and firing angles. The objective is to determine the optimal operating point for each parameter based on the selected criteria. In the previous discussion, we have highlighted the selected optimal reference current and shown that there is an optimal voltage for each speed. Once the optimal reference current and the voltage level was set for the corresponding speed range, the remaining variable to be optimized is the firing angles. This would be the most influential parameter to optimize for the controller. The best way to determine the optimal firing angles is to simulate it for all possible range of design parameters.

The data collection is performed using massive simulation under the following conditions.

(i) Turn on angle is varied between $12 \circ$ to $30^{\circ}$ in $1^{\circ}$ increments. The value of turn on angle is chosen before and after alignment position. The turn on 
TABLE 2: Optimal angles at different speed and voltage.

\begin{tabular}{|c|c|c|c|c|c|}
\hline \multicolumn{6}{|c|}{$\omega=25 \mathrm{rad} / \mathrm{s}$} \\
\hline Volt & Turn on $\theta_{\text {on }}$ & Turn off $\theta_{\text {off }}$ & Dwell $\left(\theta_{\text {off }}-\theta_{\text {on }}\right) \theta_{d}$ & Total instantane ous power & Instantan eous copper losses \\
\hline $50 \mathrm{~V}$ & 16 & 34 & 18 & 51.7 & 15.3 \\
\hline $100 \mathrm{~V}$ & 18 & 34 & 16 & 196.6 & 56.2 \\
\hline $150 \mathrm{~V}$ & 22 & 34 & 12 & 339.3 & 72.5 \\
\hline \multirow[t]{2}{*}{$325 \mathrm{~V}$} & 29 & 37 & 8 & 933.8 & 111.7 \\
\hline & 19 & 41 & 22 & 1247.9 & 173.8 \\
\hline \multirow[t]{2}{*}{$500 \mathrm{~V}$} & 31 & 38 & 7 & 1662.7 & 140.7 \\
\hline & 21 & 41 & 20 & 2085.1 & 194.6 \\
\hline \multicolumn{6}{|c|}{$\omega=35 \mathrm{rad} / \mathrm{s}$} \\
\hline $50 \mathrm{~V}$ & 16 & 35 & 19 & 45.7 & 12.7 \\
\hline $100 \mathrm{~V}$ & 15 & 34 & 19 & 178 & 47.4 \\
\hline $150 \mathrm{~V}$ & 19 & 34 & 15 & 331.2 & 71.1 \\
\hline \multirow[t]{2}{*}{$325 \mathrm{~V}$} & 27 & 36 & 9 & 846.4 & 93.8 \\
\hline & 17 & 42 & 25 & 1171.5 & 159.3 \\
\hline \multirow[t]{2}{*}{$500 \mathrm{~V}$} & 29 & 37 & 8 & 1531.7 & 121.9 \\
\hline & 22 & 42 & 20 & 1951.5 & 177.8 \\
\hline \multicolumn{6}{|c|}{$\omega=45 \mathrm{rad} / \mathrm{s}$} \\
\hline $50 \mathrm{~V}$ & 15 & 35 & 20 & 39.7 & 9.7 \\
\hline $100 \mathrm{~V}$ & 13 & 34 & 21 & 160.9 & 39.6 \\
\hline $150 \mathrm{~V}$ & 16 & 34 & 18 & 320 & 69.2 \\
\hline \multirow[t]{2}{*}{$325 \mathrm{~V}$} & 24 & 36 & 12 & 849.5 & 96.1 \\
\hline & 16 & 43 & 27 & 1098.4 & 145.7 \\
\hline \multirow[t]{2}{*}{$500 \mathrm{~V}$} & 28 & 37 & 9 & 1460.2 & 112.7 \\
\hline & 19 & 42 & 23 & 1858.5 & 166.6 \\
\hline \multicolumn{6}{|c|}{$\omega=55 \mathrm{rad} / \mathrm{s}$} \\
\hline $50 \mathrm{~V}$ & 14 & 35 & 21 & 35.3 & 7.8 \\
\hline $100 \mathrm{~V}$ & 14 & 35 & 21 & 144.8 & 33.5 \\
\hline $150 \mathrm{~V}$ & 14 & 34 & 20 & 300 & 62.1 \\
\hline \multirow[t]{2}{*}{$325 \mathrm{~V}$} & 21 & 36 & 15 & 845.2 & 96.3 \\
\hline & 13 & 43 & 30 & 1052.7 & 136.2 \\
\hline \multirow[t]{2}{*}{$500 \mathrm{~V}$} & 26 & 37 & 11 & 1414.8 & 109.8 \\
\hline & 17 & 42 & 25 & 1794.4 & 158.8 \\
\hline
\end{tabular}

angle is projected into the motoring region to allow current to build.

(ii) The turn off angle is varied between $25^{\circ}$ to $44^{\circ}$ in $1^{\circ}$ increments for each of the constant turn on angle chosen above.

The data are collected at different speed and terminal voltage level: $25 \mathrm{rad} / \mathrm{s}, 35 \mathrm{rad} / \mathrm{s}, 45 \mathrm{rad} / \mathrm{s}, 55 \mathrm{rad} / \mathrm{s}$, and $50 \mathrm{~V}$ $100 \mathrm{~V}, 150 \mathrm{~V}, 325 \mathrm{~V}$, and $500 \mathrm{~V}$.

The optimization results for maximization of percentage power generated based on the above method are shown in Figure 9. The optimal turn off angle is selected for each value of turn on angle between $12^{\circ}$ and $30^{\circ}$. Also as seen in Figure 9, an optimal turn on angle exists at each voltage level and speed.

Table 2 tabulates the optimal angles at each voltage level and speed. The percentage power generated can be represented as a function of firing angles and speed at different voltage level. The optimal voltage level for speed
TABLE 3: Characterization of speed and voltage level.

\begin{tabular}{lc}
\hline Speed, $\omega(\mathrm{rad} / \mathrm{s})$ & Voltage (volt) \\
\hline $25 \mathrm{rad} / \mathrm{s} \leq \omega$ & $50 \mathrm{~V}$ \\
$25 \mathrm{rad} / \mathrm{s}<\omega \leq 50 \mathrm{rad} / \mathrm{s}$ & $100 \mathrm{~V}$ \\
$50 \mathrm{rad} / \mathrm{s}<\omega \leq 55 \mathrm{rad} / \mathrm{s}$ & $150 \mathrm{~V}$ \\
\hline
\end{tabular}

range between $25 \mathrm{rad} / \mathrm{s}$ to $55 \mathrm{rad} / \mathrm{s}$ can be grouped as in Table 3.

\section{Observations and Analysis}

5.1. Non-Continuous Phase Current Profile. Simulation results obtained based on Table 2 includes a non-continuous current profile when three phases are considered. Overlapping is not an issue for the optimal range of angles obtained between $50 \mathrm{~V}$ to $150 \mathrm{~V}$ where machine operates in single pulse mode. The problem arises during current chopping 


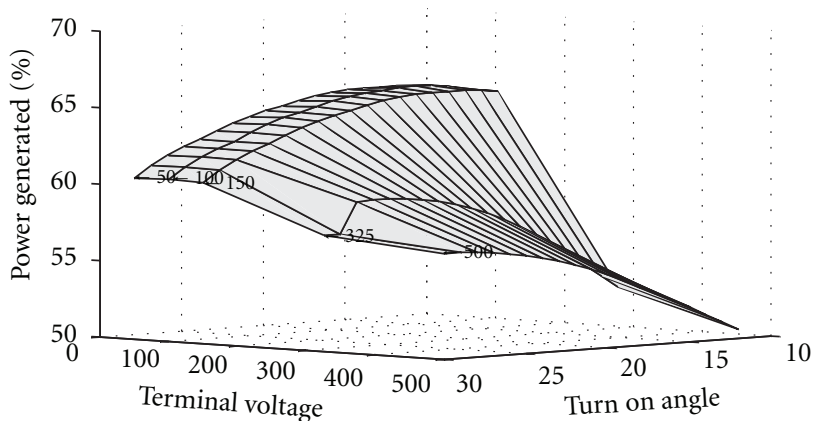

(a) $35 \mathrm{rad} / \mathrm{s}$

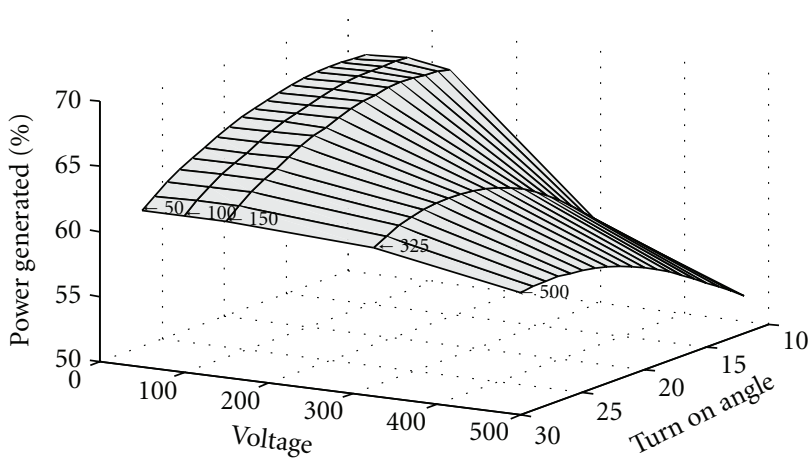

(b) $45 \mathrm{rad} / \mathrm{s}$

Figure 9: Maximization of parameters for best generating operation at each voltage and speed (a) $35 \mathrm{rad} / \mathrm{s}$, (b) $45 \mathrm{rad} / \mathrm{s}$.

mode at higher voltage level where the turn on angle is placed along the decreasing inductance profile to aid in increase of current to its reference value. This reduces the dwell angle $\theta_{d}$, which is the difference between turn off and turn on angle:

$$
\theta_{d}=\theta_{\mathrm{off}}-\theta_{\mathrm{on}}
$$

The percentage of power generated is higher; however the phase current does not overlap between adjacent phases resulting in non-continuous current profile, thus increase torque ripple and losses.

Torque pulsation occurs at commutation between the adjacent phases [26]. Figure 10 shows the current and torque profile for the same speed range, voltage, and turn on angle. In this case only turn off angle is varied from $37^{\circ}$ to $43^{\circ}$. Having complete overlap between the phase current reduces torque ripple as in Figures 10(b) and 10(d) [33].

5.2. Continuous Current Profile. To address the issue of non-continuous current profile, the overlapping between adjacent phases has to be taken into account. The maximum percentage of power generated will reduce although the overall generated power (power profile) increases.

The new value of optimal angles for voltage of $325 \mathrm{~V}$ and $500 \mathrm{~V}$ at speed ranging from $25 \mathrm{rad} / \mathrm{s}$ to $55 \mathrm{rad} / \mathrm{s}$ is highlighted in Table 2. The value of optimal angles is taken at full overlap of phase current since it shows significant reduction in torque ripple. The overlap between adjacent phases is achieved when turn on angle is on the increasing inductance profile with dwell angle of more than $20^{\circ}$.

Based on Table 2 it can be concluded that optimal angles occur at each speed and voltage level.

\section{Algorithm}

From the previous investigations, we can conclude that the percentage of power generated is a function of firing angles and speed for different voltage level:

$$
P_{\text {gen }}=P_{\text {gen }}\left(\theta_{d}, \omega\right) \text {. }
$$

It should also be pointed out that the change in the optimal turn off angle is small; thus it can remain constant at each speed and voltage level. Therefore a controller model of dwell angle can be defined as a function of speed, respectively.

Figure 11 depicts the optimal dwell angle at each voltage and speed taking into account the criteria of overlapping phase currents. Least square method and Vandermonde matrix is used to obtain the function of dwell angle in terms of speed using a commercial software package, MATLAB (R2010b, The Mathworks Inc, Natick, MA):

$$
\theta_{d}^{\text {optimal }}=a \omega^{3}+b \omega^{2}+c \omega+d,
$$

where $\omega$ is the speed in $\mathrm{rad} / \mathrm{s}$ and $a, b, c$ and $d$, are the coefficients determined using curve fitting procedure. Such function can be expressed in matrix form as in (10).

Based on Table 3 and (9), a closed-loop control can be developed to provide the optimal dwell angle for speeds ranging between $25 \mathrm{rad} / \mathrm{s}$ to $55 \mathrm{rad} / \mathrm{s}$. The controller allows the voltage to be selected in order to maintain the high percentage of power generated. Figure 12 illustrates the proposed control scheme to implement the optimal control algorithm. In this way, the machine can accommodate a change in wind velocity and provide the highest percentage of power generated:

$$
\begin{aligned}
& \theta_{d_{-} 50 \mathrm{~V}} \\
& \theta_{d_{-} 100 \mathrm{~V}} \\
& \theta_{d_{\_} 150 \mathrm{~V}} \\
& \theta_{d_{\_} 325 \mathrm{~V}} \\
& \theta_{d_{-} 500 \mathrm{~V}}
\end{aligned}=\left[\begin{array}{ccccc}
0 & 0 & 0 & 0.1 & 16 \\
0 & 0 & -0.0075 & 0.77 & 1.4 \\
0 & 0 & -0.0025 & 0.47 & 1.8 \\
0 & 0.00033 & -0.04 & 1.8 & -3 \\
0 & -0.00067 & 0.085 & -3.3 & 59
\end{array}\right]\left[\begin{array}{c}
\omega^{4} \\
\omega^{3} \\
\omega^{2} \\
\omega \\
1
\end{array}\right] .
$$

\section{Verification Through Simulation}

The algorithms proposed in Section 6 were implemented in simulation to confirm proper operation before it can be developed experimentally. The SRG is intended for the application in wind energy application. Hence, the focus is to maximize the generation as much as possible during lowspeed range. Figure 13 shows the result when a step input speed is applied. The proposed algorithm adjusts to the required voltage level in order to provide high percentage of generated power. The control technique provides the highest percentage of power generated by varying the voltage level within the speed range. Figure 14 shows results of the implemented control technique which corresponds well with the result obtained using massive simulation. 


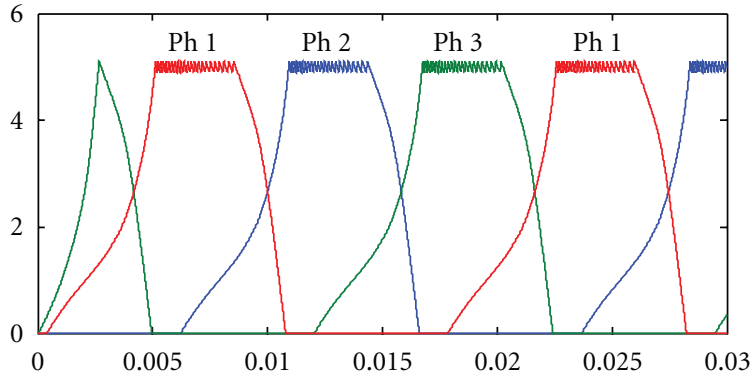

(a)

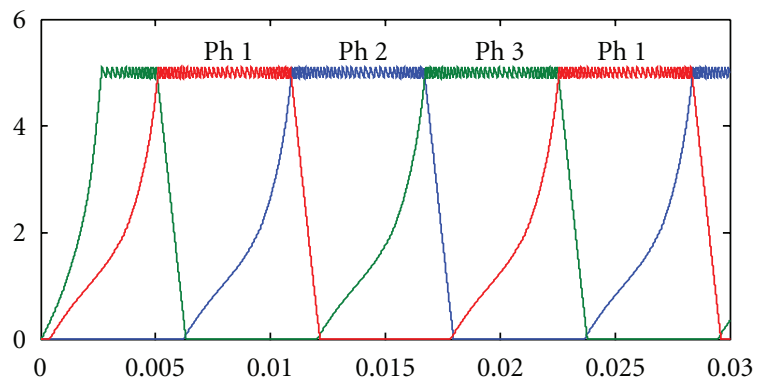

(c)

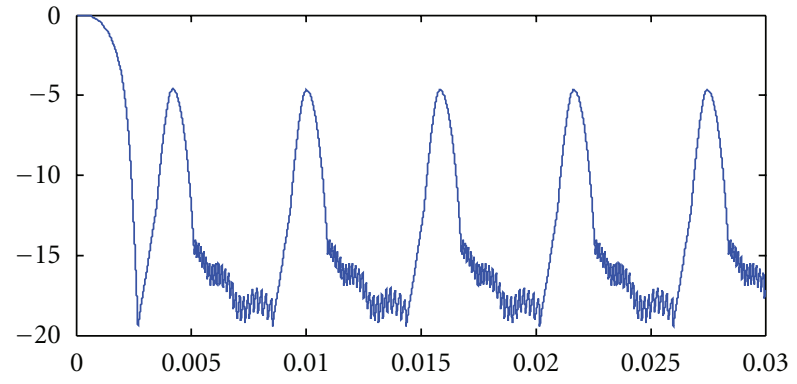

(b)

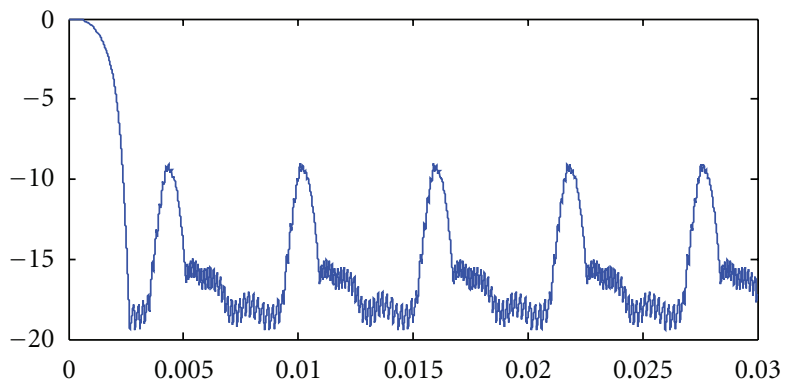

(d)

FiguRE 10: Current and torque profile during chopping mode taking into account the overlapping between adjacent phases at $325 \mathrm{~V}$ and speed $45 \mathrm{rad} / \mathrm{s}$ (a) current and (b) torque at Ton $=16 \mathrm{deg}$, Toff $=37 \mathrm{deg}$, (c) current and (d) torque at Ton $=16 \mathrm{deg}$, Toff $=43 \mathrm{deg}$.

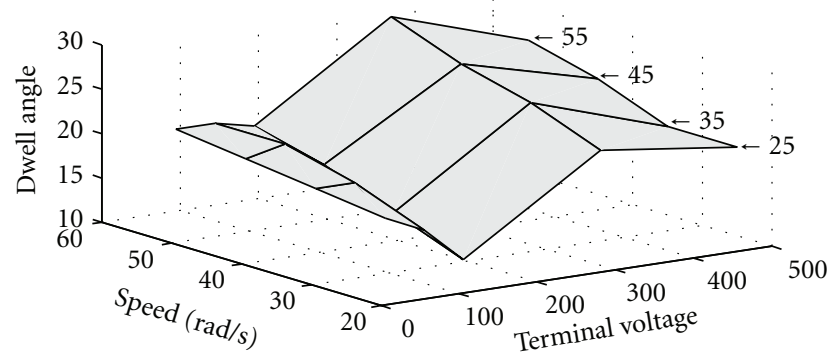

FIGURE 11: Graph showing relationship between dwell angle with speed and voltage level.

\section{Conclusion}

In this paper, three parameters have been used to evaluate the performance of the machine in terms of highest percentage of power generated. They are the terminal voltage, reference current, and firing angles. Although all parameters have been analyzed, the controlled and most influential parameter that affects the percentage of power generated is the firing angles. It occurs at each speed range and voltage level. It has also been shown that during low- and medium- speed range, the turn off angle remains constant. Therefore, the relation of percentage of power generated can be represented as a function of dwell angle and speed at different level of voltage.

The developed function provides the optimal turn on angle by rearranging (7):

$$
\theta_{\mathrm{on}}^{\text {optimal }}=\theta_{\mathrm{off}}^{\text {optimal }}-\theta_{d}^{\text {optimal }}
$$

Since the voltage level affects the shape of phase current, a control method was developed to maintain the highest percentage of power generated by varying the voltage within the low- and medium-speed range.

Single pulse mode operation can be achieved by using a low voltage level as current cannot reach its reference value. Higher percentage of power generated is obtained as compared to current chopping mode. High voltage level is not suitable for low- and medium-speed since it does not benefit in terms of generated power. The power generated is below $60 \%$. Operating the machine in single pulse mode during low- and medium-speed would result in reduced excitation hence increasing generation stage.

The outcome of the best generating operation for a 3phase 12/8 SRG operating between speed range of $25 \mathrm{rad} / \mathrm{s}$ and $55 \mathrm{rad} / \mathrm{s}$ can be summarized as follows.

(i) Optimal range of voltage is between $50 \mathrm{~V}$ and $150 \mathrm{~V}$. Higher voltage gives higher amount of generated power at the expense of higher excitation.

(ii) The change of optimal turn off angle is minimal hence to maintain the optimal dwell angle it is made constant. It should also be pointed out that a small change in turn off angle results in a small change of percentage of power generated. Therefore, the optimal turn off angle is chosen as 35 ofor the optimal range of voltage level.

(iii) Instead of using one voltage level, a high percentage of generated power can be maintained by changing its optimal voltage as speed varies. 


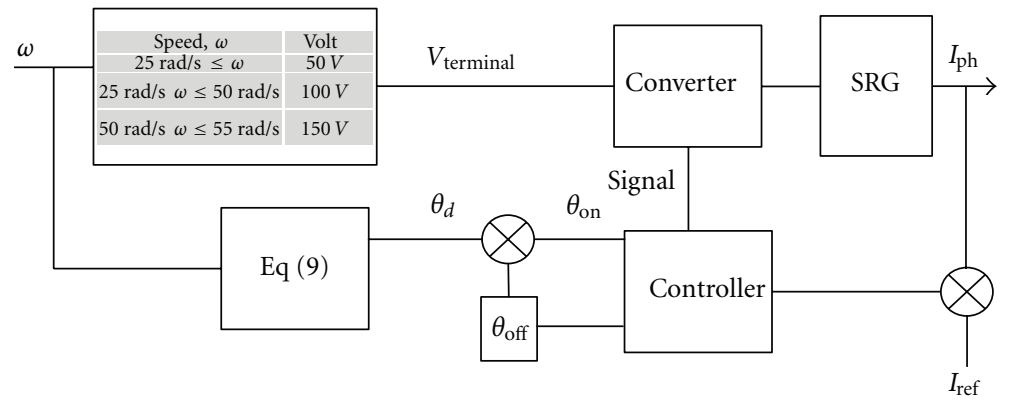

FIGURE 12: Schematic diagram of the proposed control algorithm to provide optimal firing angle at selected speed and voltage level.

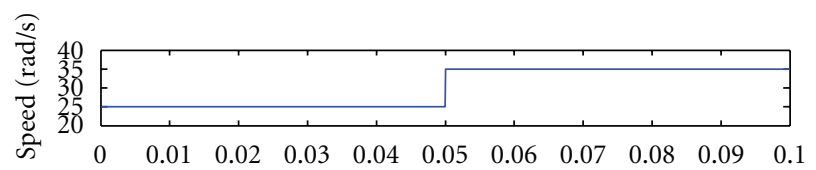

(a)

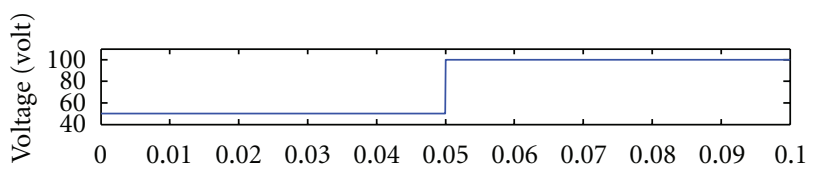

(b)

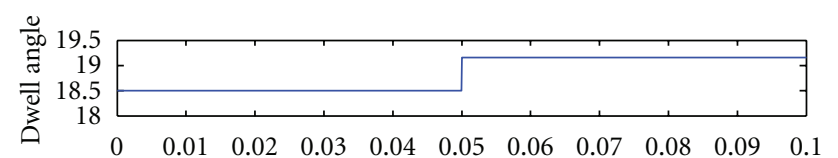

(c)

FIGURE 13: Simulation result of the proposed algorithm when a step input is applied.

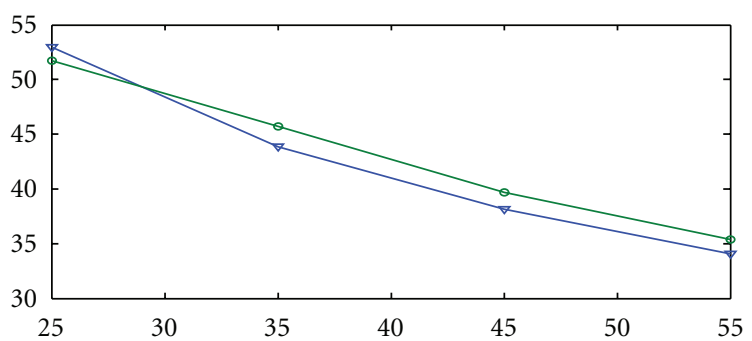

$\rightarrow 50 \mathrm{~V}$ simulation

$\rightarrow 50 \mathrm{~V}$ equation

(a)

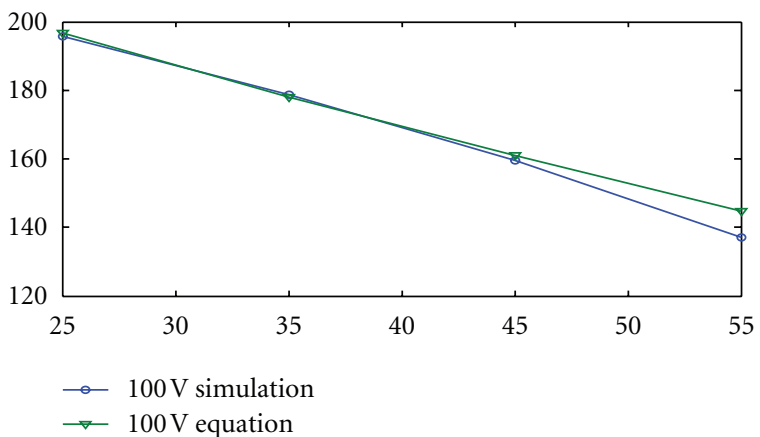

(c)

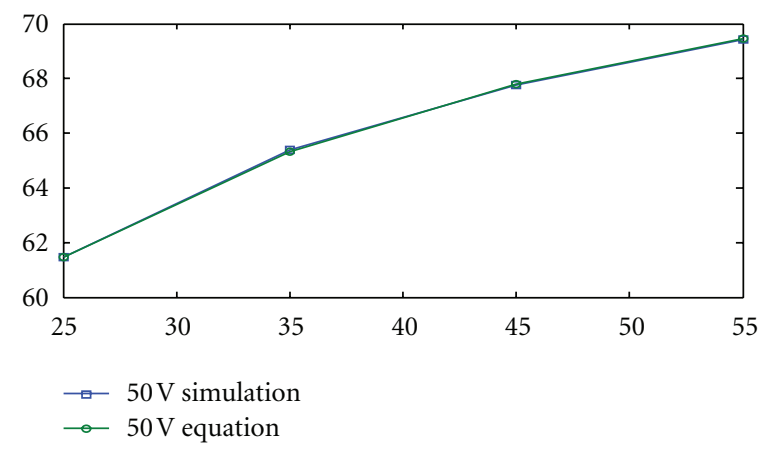

(b)

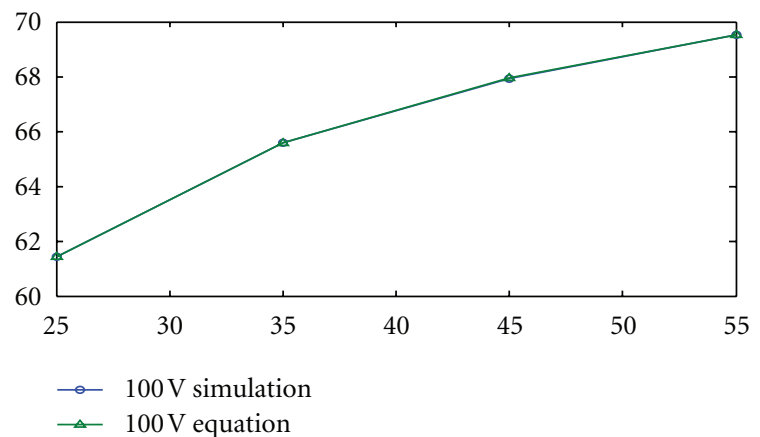

(d)

FIGURE 14: Comparison of result using the proposed algorithm with result from massive simulation (a) total instantaneous power at $50 \mathrm{~V}$, (b) highest \% power generated at $50 \mathrm{~V}$, (c) total instantaneous power at $100 \mathrm{~V}$, and (d) Highest \% power generated at $100 \mathrm{~V}$. 
The simulation results have demonstrated that the proposed algorithm can be used to provide highest percentage of power generated. Therefore, the findings in this paper will aid in development of SRG by allowing user to choose the best generating operation in low- and medium-speed range.

\section{References}

[1] S. E. Schulz and K. M. Rahman, "High-performance digital PI current regulator for EV switched reluctance motor drives," IEEE Transactions on Industry Applications, vol. 39, no. 4, pp. 1118-1126, 2003.

[2] W. Shuanghong, Z. Qionghua, M. Zhiyuan, and Z. Libing, "Implementation of a 50-kW four-phase switched reluctance motor drive system for hybrid electric vehicle," IEEE Transactions on Magnetics, vol. 41, no. 1, pp. 501-504, 2005.

[3] X. D. Xue, K. W. E. Cheng, J. K. Lin et al., "Optimal control method of motoring operation for SRM drives in electric vehicles," IEEE Transactions on Vehicular Technology, vol. 59, no. 3, pp. 1191-1204, 2010.

[4] X. D. Xue, K. W. E. Cheng, T. W. Ng, and N. C. Cheung, "Multi-objective optimization design of in-wheel switched reluctance motors in electric vehicles," IEEE Transactions on Industrial Electronics, vol. 57, no. 9, pp. 2980-2987, 2010.

[5] S. R. MacMinn and W. D. Jones, "Very high speed switchedreluctance starter-generator for aircraft engine applications," in Proceedings of the IEEE National Aerospace and Electronics Conference, pp. 1758-1764, Dayton, Ohio, USA, May 1989.

[6] E. Richter and C. Ferreira, "Performance evaluation of a 250 kW switched reluctance starter generator," in Proceedings of the Conference Record of the IEEE Industry Applications, pp. 434440, Orlando, Fla, USA, October 1995.

[7] Y. Wang, W.-W. Zhou, L. Yu, and X.-Y. Yang, "Research on the precise control method based on the new style PWM with variable pulse width," in Proceedings of the International Conference on Embedded Software and Systems, pp. 488-495, Sichuan, China, July 2008.

[8] D. Wen and L. Deliang, "A fast analytical model for an integrated switched reluctance starter/generator," IEEE Transactions on Energy Conversion, vol. 25, no. 4, pp. 948-956, 2010.

[9] Q. Bingni, S. Jiancheng, L. Tao, and Z. Hongda, "Mutual coupling and its effect on torque waveform of even number phase switched reluctance motor," in Proceedings of the 11th International Conference on Electrical Machines and Systems, pp. 3405-3410, Wuhan, China, October 2008.

[10] K. Ogawa, N. Yamamura, and M. Ishda, "Study for small size wind power generating system using switched reluctance generator," in Proceedings of the IEEE International Conference on Industrial Technology, pp. 1510-1515, Mumbai, India, December 2006.

[11] C. Hao, Z. Dong, and M. Xianjun, "Analysis of threephase 12/8 structure switched reluctance motor drive," in Proceedings of the IEEE International Symposium on Industrial Electronics Proceedings, pp. 781-785, Busan, Korea, June 2001.

[12] H. Zhao, Y. Lingzhi, P. Hanmei, and Z. Kunyan, "Research and control of SRG for variable-speed wind energy applications," in Proceedings of the IEEE 6th International Power Electronics and Motion Control Conference (IPEMC '09), pp. 2238-2243, Wuhan, China, May 2009.

[13] A. Fleury, D. Andrade, E. S. L. Oliveira et al., "Study on an alternative converter performance for switched reluctance generator," in Proceedings of the 34th Annual Conference of the IEEE Industrial Electronics Society, pp. 1409-1414, Orlando, Fla, USA, November 2008.

[14] P. C. Desai, M. Krishnamurthy, N. Schofield, and A. Emadi, "Novel switched reluctance machine configuration with higher number of rotor poles than stator poles: concept to implementation," IEEE Transactions on Industrial Electronics, vol. 57, no. 2, pp. 649-659, 2010.

[15] H. C. Lovatt and J. M. Stephenson, "Influence of number of poles per phase in switched reluctance motors," IEE Proceedings B, vol. 139, no. 4, pp. 307-314, 1992.

[16] L. Moreau, M. Machmoum, and M. E. Zaïm, "Design of lowspeed slotted switched reluctance machine for wind energy applications," Electric Power Components and Systems, vol. 34, no. 10, pp. 1139-1156, 2006.

[17] M. A. Mueller, "Design and performance of a 20kW, 100rpm, switched reluctance generator for a direct drive wind energy converter," in Proceedings of the IEEE International Conference on Electric Machines and Drives, pp. 56-63, San Antonio, Tex, USA, May 2005.

[18] M. A. Mueller, "Design of low speed switched reluctance machines for wind energy converters," in Proceedings of the 9th International Conference on Electrical Machines and Drives, pp. 60-64, Canterbury, UK, September 1999.

[19] I. Kioskeridis and C. Mademlis, "Optimal efficiency control of switched reluctance generators," IEEE Transactions on Power Electronics, vol. 21, no. 4, pp. 1062-1072, 2006.

[20] Y. Sozer and D. A. Torrey, "Closed loop control of excitation parameters for high speed switched-reluctance generators," IEEE Transactions on Power Electronics, vol. 19, no. 2, pp. 355$362,2004$.

[21] P. Asadi, M. Ehsani, and B. Fahimi, "Design and control characterization of switched reluctance generator for maximum output power," in Proceedings of the 21st Annual IEEE Applied Power Electronics Conference and Exposition, pp. 1639-1644, Dallas, Tex, USA, March 2006.

[22] I. Kioskeridis and C. Mademlis, "Maximum efficiency in single-pulse controlled switched reluctance motor drives," IEEE Transactions on Energy Conversion, vol. 20, no. 4, pp. 809-817, 2005.

[23] A. Takahashi, H. Goto, K. Nakamura, T. Watanabe, and O. Ichinokura, "Characteristics of $8 / 6$ switched reluctance generator excited by suppression resistor converter," IEEE Transactions on Magnetics, vol. 42, no. 10, pp. 3458-3460, 2006.

[24] A. Fleury, D. A. de Andrade, F. dos Santos e Silva, and J. L. Domingos, "Switched reluctance generator for complementary wind power generation in grid connection," in Proceedings of the IEEE International Electric Machines \& Drives Conference, pp. 465-470, Antalya, Turkey, May 2007.

[25] H. Keunsoo, K. Rae-Young, and R. Ramu, "Position estimation in switched reluctance motor drives using the first switching harmonics through fourier series," IEEE Transactions on Industrial Electronics, vol. 58, no. 12, pp. 5352-5360, 2011.

[26] C. Mademlis and I. Kioskeridis, "Gain-scheduling regulator for high-performance position control of switched reluctance motor drives," IEEE Transactions on Industrial Electronics, vol. 57, no. 9, pp. 2922-2931, 2010.

[27] R. Cárdenas, R. Peña, M. Pérez, J. Clare, G. Asher, and P. Wheeler, "Control of a switched reluctance generator for variable-speed wind energy applications," IEEE Transactions on Energy Conversion, vol. 20, no. 4, pp. 781-791, 2005.

[28] B. Parreira, S. Rafael, A. J. Pires, and P. J. C. Branco, "Obtaining the magnetic characteristics of an $8 / 6$ switched reluctance 
machine: from FEM analysis to the experimental tests," IEEE Transactions on Industrial Electronics, vol. 52, no. 6, pp. 16351643, 2005.

[29] V. K. Sharma, S. S. Murthy, and B. Singh, "An improved method for the determination of saturation characteristics of switched reluctance motors," IEEE Transactions on Instrumentation and Measurement, vol. 48, no. 5, pp. 995-1000, 1999.

[30] P. Lobato, S. Rafael, J. Martins, and A. J. Pires, "Flux-linkage characteristics models for switched reluctance machines," in Proceedings of the 36th Annual Conference of the IEEE Industrial Electronics Society (IECON '10), pp. 847-852, Glendale, Ariz, USA, November 2010.

[31] Y. Hayashi and T. J. E. Miller, "A new approach to calculating core losses in the SRM," IEEE Transactions on Industry Applications, vol. 31, no. 5, pp. 1039-1046, 1995.

[32] H. Hannoun, M. Hilairet, and C. Marchand, "Design of an SRM speed control strategy for a wide range of operating speeds," IEEE Transactions on Industrial Electronics, vol. 57, no. 9, pp. 2911-2921, 2010.

[33] T. Raminosoa, B. Blunier, D. Fodorean, and A. Miraoui, "Design and optimization of a switched reluctance motor driving a compressor for a PEM fuel-cell system for automotive applications," IEEE Transactions on Industrial Electronics, vol. 57, no. 9, pp. 2988-2997, 2010. 

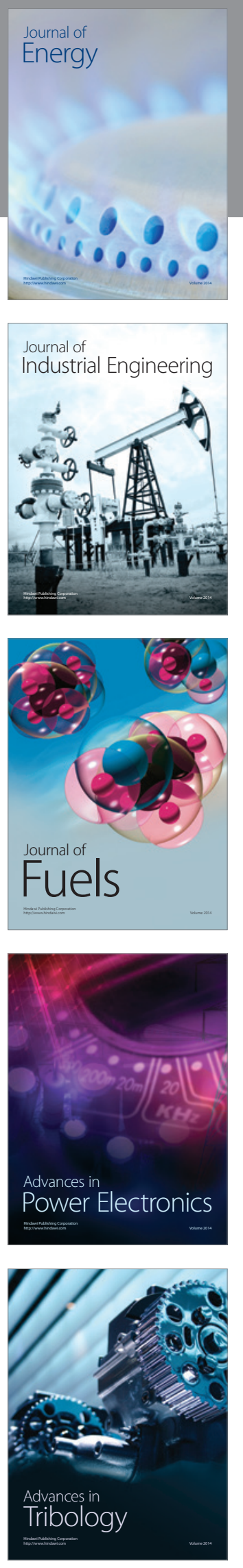
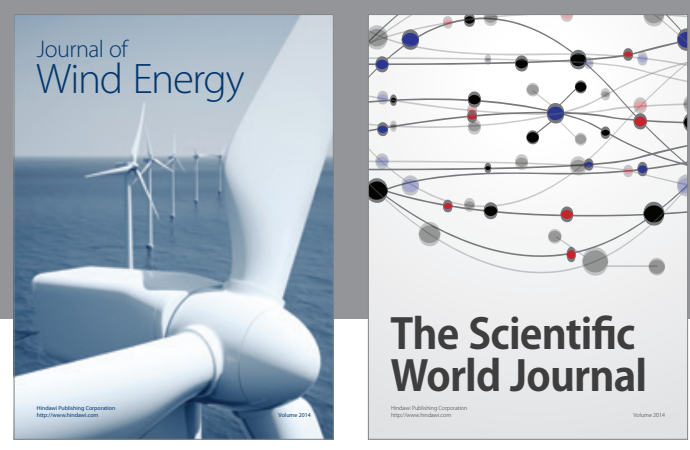

The Scientific World Journal

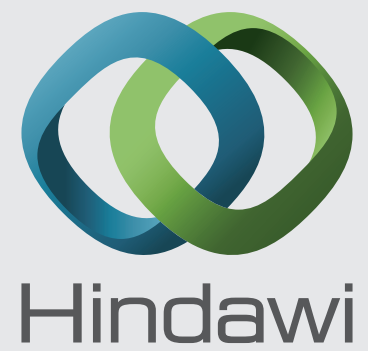

Submit your manuscripts at http://www.hindawi.com
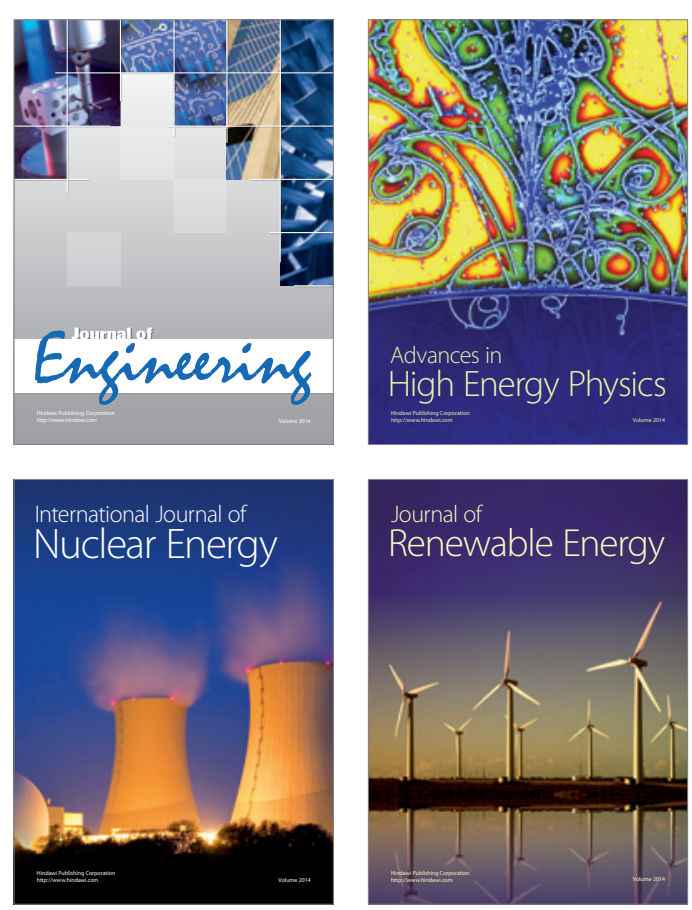

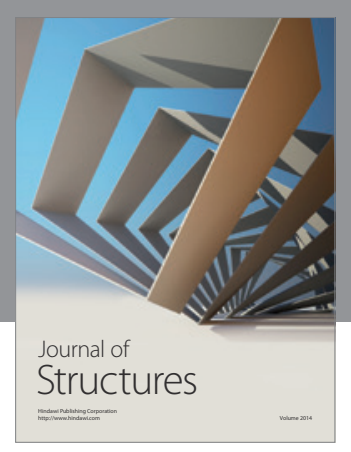

Rotating
Mechinery
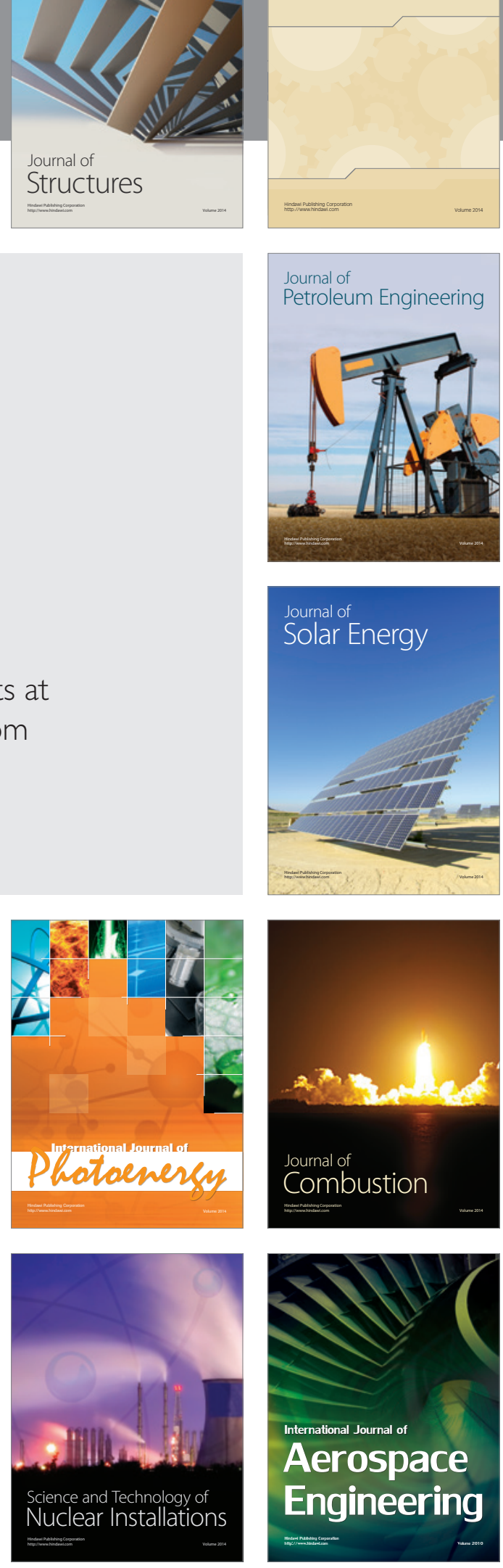